\title{
Profit Optimization of an Apparel Industry in Bangladesh by Linear Programming Model
}

\author{
F. M. Shakirullah ${ }^{1, ~ *, ~ M a i n ~ U d d i n ~ A h a m m a d ~}{ }^{1}$, Mohammed Forhad Uddin² \\ ${ }^{1}$ Department of Mathematics, Dhaka University of Engineering and Technology, Gazipur, Bangladesh \\ ${ }^{2}$ Department of Mathematics, Bangladesh University of Engineering and Technology, Dhaka, Bangladesh \\ Email address: \\ shakirbsl@yahoo.com (F. M. Shakirullah),main3737@gmail.com (M. U. Ahammad), kforhad77@gmail.com (M. F. Uddin) \\ ${ }^{*}$ Corresponding author
}

\section{To cite this article:}

F. M. Shakirullah, Main Uddin Ahammad, Mohammed Forhad Uddin. Profit Optimization of an Apparel Industry in Bangladesh by Linear Programming Model. American Journal of Applied Mathematics. Vol. 8, No. 4, 2020, pp. 182-189. doi: 10.11648/j.ajam.20200804.13

Received: March 11, 2020; Accepted: March 27, 2020; Published: July 17, 2020

\begin{abstract}
Efficient use of resources in production stages is very much important for every industry. For sustainable development of industry, efficacious management decision making techniques may be employed to analyze and utilize resources. Linear programming, as a quantitative decision-making tool, can be engaged by the managements for enhancing resource utilization along with increasing profit and decreasing cost. Proper allocation and usage of resources like available processing time at different stages, labors, materials such as fabrics and sewing threads is the tacit factor for profitability of an apparel manufacturing firm. Apparel processes such as cutting, sewing, washing, dying, trimming and finishing are needed to be optimized for lead time management. This study formulated a linear programming model to maximize profit and minimize cost of apparel industries. The model also optimizes the utilization of resources. This paper considers a knit garment manufacturing unit of Bangladesh which is situated in Gazipur district. Data containing monthly resources utilization amount, product volume, profit per unit on different types of products have been collected from the case industry. The data collected was used as the parameters of the proposed linear programming to validate the model. The model was implemented and solved by the Microsoft Excel Solver as well by AMPL. This research revealed that the profit of the case company can be increased by $22 \%$ when there is sufficient demand and that can be $12.33 \%$ when clients' requests are to be met. On the other hand, cost may be decreased by $37 \%$ by using the LPP model.
\end{abstract}

Keywords: Apparel Industry, Linear Programming, Resource Utilization, Solver, Optimization

\section{Introduction}

The apparel sector of Bangladesh has got a greater attention than any other industry for its rapid growth and major share in foreign exchange earnings. Bangladesh is the second largest apparel exporter in the world after China. The market share of Bangladesh, in the $\$ 447$ billion global garment earnings is 6.5 percent, according to data from the International Trade Statistics of the World Bank in 2017. Its contribution to the national economy by creating huge employment opportunities and reducing poverty through socioeconomic development is beyond anticipation. The Ready-Made Garments (RMG) holds almost 14.07 percent of the GDP of Bangladesh as well as the 83 percent of the total export earnings. During the last three decades, the RMG industry contributed significantly through creation of physical infrastructure which is demonstrated by $4560 \mathrm{RMG}$ units along with the development of human capital as around 4 million work force are directly involved in this industry. It has also contributed tremendously through empowering women as almost 90 percent of its labor force is female.

Table 1. Global Market Share of RMG.

\begin{tabular}{lll}
\hline Country & $\begin{array}{l}\text { Global Market Share } \\
(\%)\end{array}$ & $\begin{array}{l}\text { Export Earnings in } \\
\text { \$ Billion }\end{array}$ \\
\hline China & 34.4 & 158 \\
Bangladesh & 6.5 & 29 \\
Vietnam & 5.9 & 27 \\
India & 4.1 & 18 \\
Turkey & 3.3 & 15 \\
Indonesia & 1.8 & 8 \\
Cambodia & 1.6 & 7 \\
\hline
\end{tabular}

Source: WTO, 2017

However, efficient supply chain management with proper 
utilization of scarce resources in apparel industry of Bangladesh is necessary to face its future challenges in formidable global competition. Bangladesh's RMG exports to major destinations, including the European Union, Canada and some other obsolete markets, have risen negatively in the first quarter (Q1) of the current fiscal year (2019-20).

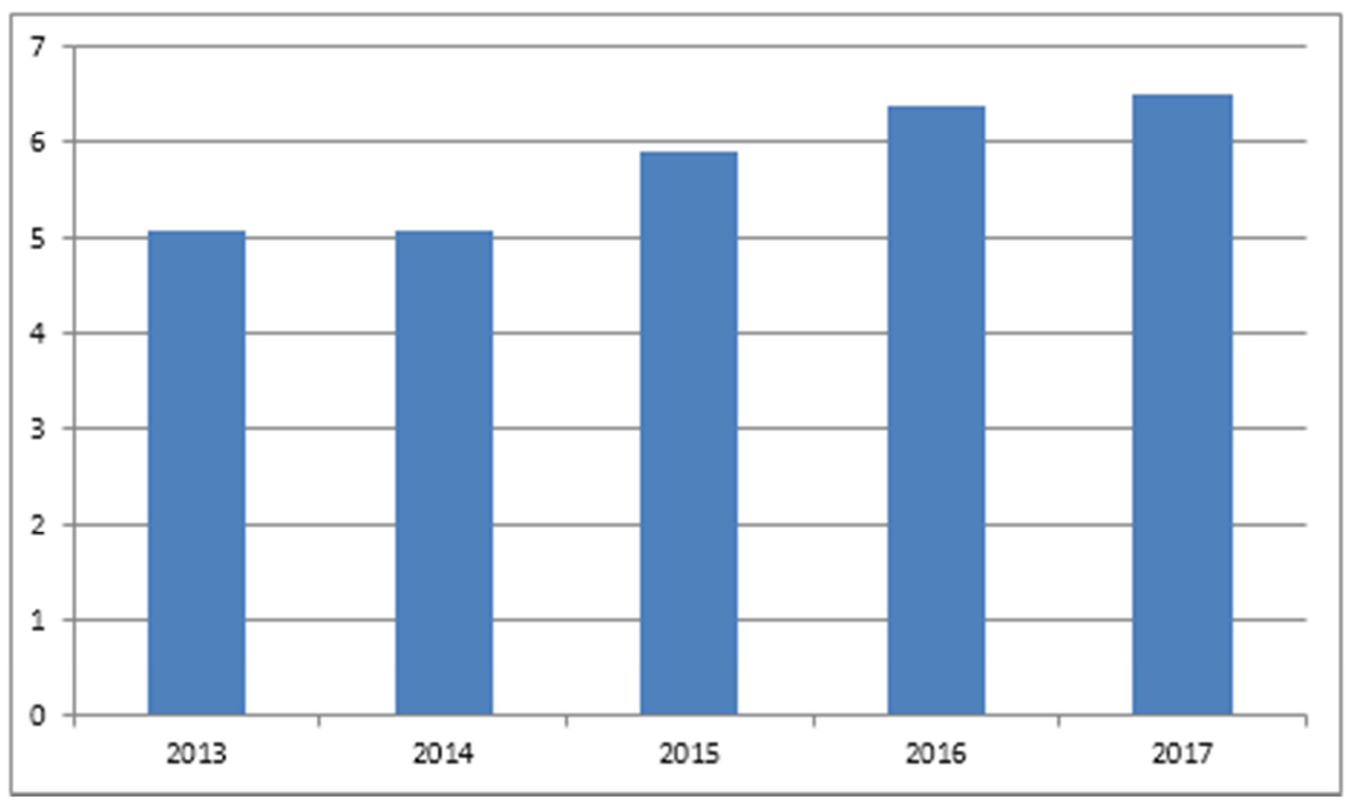

Figure 1. Bangladesh's share of the global apparel market (Source: WTO, 2018).

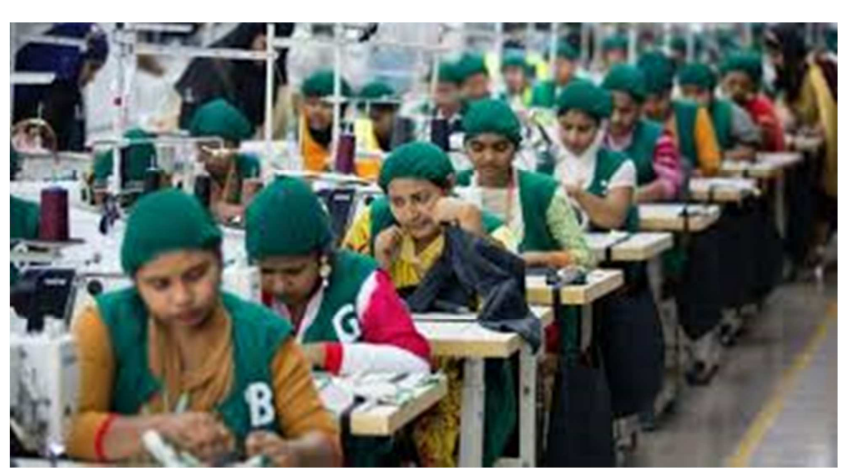

Figure 2. Garments production activities on factory floor.

According to the latest report by the World Trade Organization (WTO), Bangladesh currently accounts for $6.4 \%$ of the global garment market and Vietnam has $6.2 \%$. Industrialists are thinking that the sector will show negative growth in the coming months. At the end of this financial year, if the exports do not turn away from this downward trend, Bangladesh may lose its second position to Vietnam in the global apparel market. On the other hand, Myanmar that developed a lot in a short span of time, is coming up as a major competitor of Bangladesh in the global apparel market.

\section{Literature Review}

Uddin and Sano [1] discussed the benefit and importance of a supply chain with co-ordination mechanism. They demonstrated that the individual profit as well as joint profit could be increased by a coordination mechanism even though the demand function in non-linear. Jokar and Sajadieh [2] discussed a vendor-buyer integrated production inventory model considering JELS policy with price sensitive demand of the customer. Qin et al. [3] considered volume discounts and franchise fees as coordination mechanism in a system of supply chain with single supplier and single buyer with price sensitive demand. Uddin and Sano [4] considered an integrated multi-product, multi-facility, and multi-customer location production problem. By formulating a Mixed Integer Linear Fractional Programming (MILFP) model they maximize the ratio of return on investment of the distribution network.

Uddin and Sano [5] developed a Mixed Integer Programming (MIP) problem-based vendor-buyer multiple products-consumers, facility selection problem with a pricesensitive linear demand function. They assumed that by coordinated mechanism among the members of supply chain could achieve the optimal solution and the optimal location for the warehouse. Islam et al. [6] formulated a Mixed Integer Program for manufacturer and retailer system of poultry firm in Bangladesh. They showed that the profit and selling price have very good relationship with production cost and raw material cost but no significant relation with fixed cost. Islam et al. [7] also developed Mixed Integer and Linear Fractional Program model. In this model, instead of a price sensitive linear or deterministic demand function, a price-sensitive non-linear demand function has introduced. These models shew that by coordination mechanism individual profit as well as coordinated profit can be increased and consumers' purchasing price can be reduced.

Momaya [8] discussed about the consequence of technological innovation and globalization along with the worldwide highly competitive business environment. This article shares findings about competitiveness of important 
emerging industries such as nanotechnology and biotechnology. Nandita and Hasan [9] studied the short-term forecasting methods for the garments sector of Bangladesh to find a reliable future demand for finished products or supply of raw materials for the production.

Kumar [10] discussed about a manufacturing company's endurance in an increasingly competitive market closely depends upon its ability to produce highest quality products at lowest possible cost. More specifically Ezema and Amakom [11] asserted that organizations in the world are challenged by shortages of production inputs which can consequently lead to low capacity utilization and low production outputs. The authors stated that either cost minimization or output maximization is necessary to enhance the growth and competitiveness of organizations. Yalçinsoy et al. [12] analyzed that every manufacturing company must use their resources optimally to increase their profit. However, a key challenge faced by these organizations is how to allocate scarce resources among activities. Linear programming is a method of allocating resources in an optimal way. It is one of the most widely used operations research tools to determine optimal resource utilization. Campo et al. [13] proposed a linear programming model named LIPROTEX for minimizing total costs associated with labour and inventory levels of a textile company. They implemented and solved the model using GAMS, supported on MS Excel interface which is to apply a hybrid strategy to the production plan. Woubante [14] considered the data collected from an apparel industrial unit of Ethiopia to estimate the parameters of the linear programming model derived. He solved the model by using LINGO 16.0 software and showed that the profit of the company can be improved by $59.84 \%$ when the customer orders had to be satisfied. Tesfaye et al. [15] also analyzed the data gathered from an Ethiopian apparel industry and using a linear programming model they indicated that utilization of resources of the company could be increased by $46.41 \%$ from the existing resource utilization. They also showed that the profit of the company might be increased by $145.5 \%$ by using their model.

Different products require different amount of production resources at several stages of production. They also have different selling prices and, therefore, have different unit profits. The production process may also be subjected to different conditions. The linear programming technique will be used to determine the product mix that will increase the total profit and minimize the cost. It is an efficient method for determining an optimal solution from a large number of alternatives to meet a specified objective function subject to various constraints and restrictions.

In this paper a knit garment manufacturing unit of Bangladesh has been considered which is situated in the district of Gazipur in Bangladesh. Data containing monthly resources utilization amount, product volume, profit per unit on different types of products have been collected from the case industry. The case industry is producing knit garment product of different types and styles. The data collected was used as the parameters of the proposed linear programming model. Both Woubante [14] and Tesfaye et al.
[15] used the data collected from the industries like monthly held or available resources but a company procures resources like fabrics and threads as the production requirement. Monthly available time also can be variable because number of workers may be increased or decreased as per production plan. In this paper the cost minimization along with increasing profit using the same resources used at present is proposed. Using a linear programming method, we find the optimal, or most efficient, way of using limited resources to achieve the objective of the situation. Two situations have been considered here. At first, we examined the case where there is sufficient demand for all eight products produced by the case company for huge international market demand and later, we have considered the situation where the company produces some items as per the minimum requirements of their clients to maintain long relationship with them.

\section{Model Formulation}

The way we approach the problem is the same for a wide variety of decision-making problems, and the size and complexity of the problem may differ. An LPP model consists of the followings:

Decision variables that are mathematical symbols representing levels of activity of an operation.

The objective function that is a linear mathematical relationship describing an objective of the firm, in terms of decision variables, that is to be maximized or minimized.

Constraints that are restrictions placed on the firm by the operating environment situated in linear relationships with the decision variables.

Parameters/cost coefficients that are numerical coefficients and constants used in the objective function and constraint equations.

\subsection{Basic Assumption for the LPP}

Technically, there are six additional requirements of an LPP:

We assume that conditions of certainty exist; that is, the numbers in the objective and constraints are known with certainty and do not change during the period being studied.

We also assume that proportionality exists in the objective and constraints. This means that if production of 1 unit of a product uses 5 minutes then making 10 units of that product uses 50 minutes. The third technical assumption deals with additivity, meaning that the total of all activities equals the sum of the individual activities. We make the divisibility assumption that solutions need not be in whole numbers. Instead, they are divisible and may take any fractional value.

Finally, we assume that all answers or variables are nonnegative. Negative values of physical quantities are impossible; we simply cannot produce a negative number of apparel products.

There is sufficient demand for every product produced as a result of a bigger domestic and international market for apparel products. 


\subsection{General Form of the LP Model}

In general, if $\mathrm{P}=\left(\mathrm{p}_{1}, \mathrm{p}_{2}, \mathrm{p}_{3}, \ldots, \mathrm{p}_{\mathrm{n}}\right)$ is a tuple of real numbers, then the function $f$ of real variables $X=\left(x_{1}, x_{2}\right.$, $\left.x_{3}, \ldots, x_{n}\right)$ defined by $f(X)=p_{1} x_{1}+p_{2} x_{2}+p_{3} x_{3}+\ldots+p_{n} x_{n}$ is known as a linear function. If $g$ is a linear function and $b=$ $\left(b_{1}, b_{2}, b_{3}, \ldots, b_{n}\right)$ is a tuple of real numbers, then $g(x)=b$ is called a linear equation, whereas $\mathrm{g}(\mathrm{x})(\leq, \geq) \mathrm{b}$ is called a linear inequality. A linear constraint is one that is either a linear equation or a linear inequality. A linear programming problem (LPP) is one which optimizes (maximizes or minimizes) a linear function subject to a finite collection of linear constraints. Formally, any LPP having $n$ decision variables can be written in the following form:

Maximize $\mathrm{Z}=\sum_{j=1}^{n} P_{j} X_{j}$

Subject to $\sum_{i=1}^{m} a_{i j} X_{j} \leq b_{i}, i=1,2,3, \ldots, m$

$X_{j} \geq 0, j=1,2,3, \ldots, n$

When $P_{j}, a_{i j}, b_{i}$ are constants.

The problem is to find the values of the decision variables $X_{\mathrm{j}}$ that optimize the objective function $Z$ subject to the $\mathrm{m}$ constraints and the non-negativity restrictions on the $X_{\mathrm{j}}$ variables. The resulting set of decision variables that optimize the objective function is called the optimal solution.

This study attempts to identify the existing resource utilization level and profit per month and compare them with the optimal solutions obtained from solving the LPP models developed by the MS Excel Solver and the mathematical programming language, AMPL. Two models have been developed:

i. When there is sufficient demand;

ii. When some items are produced according to the request of client for upholding long lasting relationship.

\subsection{Model with Sufficient Demand}

The model decision variables on the number of products to be produced are set as:

$\mathrm{x}_{1}=$ Girls' T-shirt;

$\mathrm{x}_{2}=$ Keiki Boy's Long-johns;

$\mathrm{x}_{3}=$ Boy's College Hoodie;

$\mathrm{x}_{4}=$ Boy's Under ware;

$\mathrm{x}_{5}=$ Girl's Cardigan;

$\mathrm{x}_{6}=$ Girl's Leggings

$\mathrm{x}_{7}=$ Girl's College Shirt;

$\mathrm{x}_{8}=$ Girl's T-shirt L/S

The linear programming model, maximizing the total profit in BD Taka is:

Maximize $\mathrm{Z}=\mathrm{a}_{1} \mathrm{x}_{1}+\mathrm{a}_{2} \mathrm{x}_{2}+\mathrm{a}_{3} \mathrm{x}_{3}+\mathrm{a}_{4} \mathrm{x}_{4}+\mathrm{a}_{5} \mathrm{x}_{5}+\mathrm{a}_{6} \mathrm{x}_{6}+\mathrm{a}_{7} \mathrm{x}_{7}+$ $\mathrm{a}_{8} \mathrm{x}_{8}$

Subject to

Fabric:

$a_{11} x_{1}+a_{12} x_{2}+a_{13} x_{3}+a_{14} x_{4}+a_{15} x_{5}+a_{16} x_{6}+a_{17} x_{7}+a_{18} x_{8} \leq b_{1}$

Thread:

$\mathrm{a}_{21} \mathrm{x}_{1}+\mathrm{a}_{22} \mathrm{x}_{2}+\mathrm{a}_{23} \mathrm{x}_{3}+\mathrm{a}_{24} \mathrm{x}_{4}+\mathrm{a}_{25} \mathrm{x}_{5}+\mathrm{a}_{26} \mathrm{x}_{6}+\mathrm{a}_{27} \mathrm{x}_{7}+\mathrm{a}_{28} \mathrm{x}_{8} \leq \mathrm{b}_{2}$

Labor:

$a_{31} x_{1}+a_{32} x_{2}+a_{33} x_{3}+a_{34} x_{4}+a_{35} x_{5}+a_{36} x_{6}+a_{37} x_{7}+a_{38} x_{8} \leq b_{3}$ Material:

$a_{41} x_{1}+a_{42} x_{2}+a_{43} x_{3}+a_{44} x_{4}+a_{45} x_{5}+a_{46} x_{6}+a_{47} x_{7}+a_{48} x_{8} \leq b_{4}$

Cutting: $a_{51} x_{1}+a_{52} x_{2}+a_{53} x_{3}+a_{54} x_{4}+a_{55} x_{5}+a_{56} x_{6}+a_{57} x_{7}+a_{58} x_{8} \leq b_{5}$ Sewing:

$a_{61} x_{1}+a_{62} x_{2}+a_{63} x_{3}+a_{64} x_{4}+a_{65} x_{5}+a_{66} x_{6}+a_{67} x_{7}+a_{68} x_{8} \leq b_{6}$ Trimming:

$a_{71} x_{1}+a_{72} x_{2}+a_{73} x_{3}+a_{74} x_{4}+a_{75} x_{5}+a_{76} x_{6}+a_{77} x_{7}+a_{78} x_{8} \leq b_{7}$ Finishing:

$a_{81} x_{1}+a_{82} x_{2}+a_{83} x_{3}+a_{84} x_{4}+a_{85} x_{5}+a_{86} x_{6}+a_{87} x_{7}+a_{88} x_{8} \leq b_{8}$ Packing:

$a_{81} x_{1}+a_{82} x_{2}+a_{83} x_{3}+a_{84} x_{4}+a_{85} x_{5}+a_{86} x_{6}+a_{87} x_{7}+a_{88} x_{8} \leq b_{8}$

Non negative restrictions: $\mathrm{x}_{1}, \mathrm{x}_{2}, \mathrm{x}_{3}, \mathrm{x}_{4}, \mathrm{x}_{5}, \mathrm{x}_{6}, \mathrm{x}_{7}, \mathrm{x}_{8} \geq 0$

\subsection{Model with Requested Demand}

The model decision variables on the number of products to be produced and the objective function are same as the previous model with sufficient demand. All constrains are also same but instead of non-negative restrictions following conditions on decision variables are imposed:

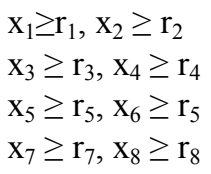

Where $r_{1}, r_{2}, r_{3}, r_{4}, r_{5}, r_{6}, r_{7}$ and $r_{8}$ are the minimum production volumes requested by the buyers keeping in touch with the industry for long time.

\section{Material and Methods}

We worked with primary data where data collection procedure was quantitative in nature and relied on face-toface interview with the members of the management, merchandisers, line supervisors and accountant of the company according to the existing record kept. The company we are considering is currently producing eight types of garments products. The study attempts to identify the existing resource utilization level and profit per month and compare them with the optimal solution obtained from solving the LPP model we developed. We have solved the model using MS Excel Solver as well as by AMPL and got the same solutions by using both the solver tools.

Relevant information collected from the case company, the time consumption to produce different products, monthly production, profit, cost and material utilization per unit. is summarized in table 2, table 3 and table 4 .

Table 2. Operation wise needed time in minute per unit.

\begin{tabular}{llllll}
\hline Style & Cutting & Sewing & Trimming & Finishing & Packing \\
\hline 1 & 0.4 & 6.4 & 0.4 & 0.4 & 0.4 \\
2 & 0.3 & 5.3 & 0.3 & 0.3 & 0.3 \\
3 & 0.5 & 5.5 & 0.5 & 0.5 & 0.5 \\
4 & 0.2 & 5.2 & 0.2 & 0.2 & 0.2 \\
5 & 0.6 & 7.6 & 0.3 & 0.6 & 0.6 \\
6 & 0.5 & 6.5 & 0.3 & 0.5 & 0.5 \\
7 & 0.4 & 5.4 & 0.4 & 0.4 & 0.4 \\
8 & 0.5 & 7.5 & 0.4 & 0.5 & 0.5 \\
\hline
\end{tabular}

Source: The case company 
Table 3. Material utilization and cost per unit.

\begin{tabular}{lllll}
\hline Style & $\begin{array}{l}\text { Fabric needed } \\
\text { (grams) }\end{array}$ & $\begin{array}{l}\text { Thread needed } \\
\text { (meter) }\end{array}$ & $\begin{array}{l}\text { Labor cost } \\
\text { (Taka) }\end{array}$ & $\begin{array}{l}\text { Material } \\
\text { cost (Taka) }\end{array}$ \\
\hline 1 & 128 & 120 & 28 & 131 \\
2 & 121 & 110 & 25 & 144 \\
3 & 246 & 220 & 65 & 220 \\
4 & 100 & 70 & 22 & 120 \\
5 & 180 & 220 & 60 & 240 \\
6 & 131 & 120 & 25 & 125 \\
7 & 165 & 120 & 30 & 155 \\
8 & 120 & 115 & 25 & 140 \\
\hline
\end{tabular}

Source: The case company

Table 4. Monthly production and profit per unit.

\begin{tabular}{lll}
\hline Style & Monthly production (pieces) & Profit per unit (Taka) \\
\hline 1 & 8000 & 42 \\
2 & 14000 & 36 \\
\hline
\end{tabular}

\begin{tabular}{lll}
\hline Style & Monthly production (pieces) & Profit per unit (Taka) \\
\hline 3 & 8000 & 40 \\
4 & 7000 & 30 \\
5 & 12000 & 35 \\
6 & 10000 & 40 \\
7 & 12000 & 30 \\
8 & 11000 & 25 \\
\hline
\end{tabular}

Source: The case company

\section{Results and Discussion}

At first, we examined the case where demand is sufficient for all eight products and later, we have considered the situation where the company produces some items as per the requests of their clients to maintain long relationship with them. Table 5, table 6 and figure 3, show the profit increases in both situations.

Table 5. Profit maximization in case of sufficient demand

\begin{tabular}{llll}
\hline Profit achieved from LPP model (Taka) & Profit achieved by Industry (Taka) & Increase in Profit (Taka) & Percentage of profit increase \\
\hline $34,20,623.45$ & $28,25,000$ & $5,95,623.45$ & $21.08 \%$ \\
\hline
\end{tabular}

Table 6. Profit maximization in case of requested production.

\begin{tabular}{llll}
\hline Profit achieved from LPP model (Taka) & Profit achieved by Industry (Taka) & Increase in Profit (Taka) & Percentage of profit increase \\
\hline $31,73,200$ & $28,25,000$ & $3,48,200$ & $12.33 \%$ \\
\hline
\end{tabular}

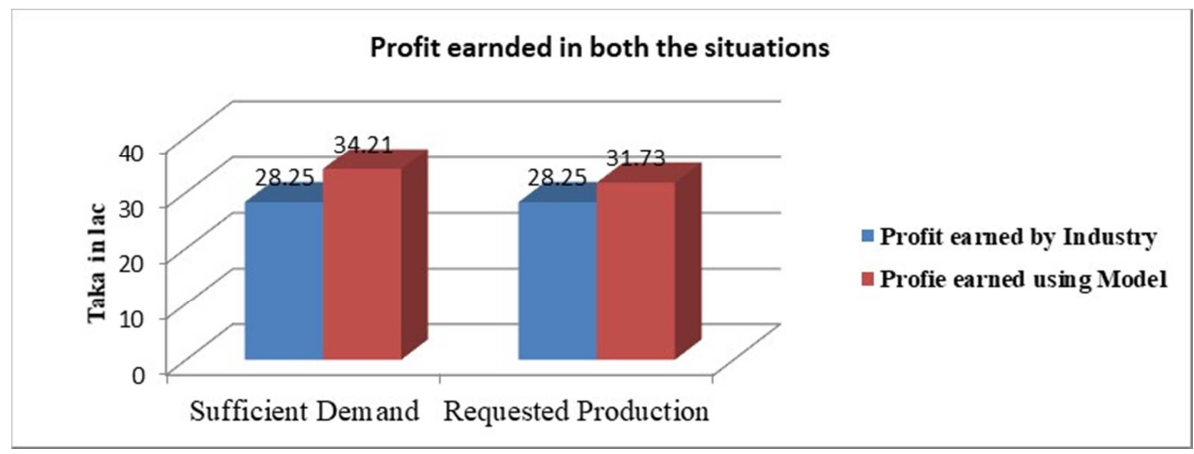

Figure 3. Profit maximization in both the cases (amount in lac Taka).

Our model has found that cost can be minimized in both the situations which is shown in table 7 , figure 4 , table 8 and figure 5 .

Table 7. Cost minimization in case of sufficient demand.

\begin{tabular}{llll}
\hline Type of cost & Used by Industry (Taka) & Used by model (Taka) & Percentage of cost decrease \\
\hline Fixed & $28,53,000$ & $23,96,240$ & 16 \\
Material & $1,31,94,000$ & $76,42,800$ & 42 \\
Total & $1,60,47,000$ & $1,00,39,040$ & 37.44 \\
\hline
\end{tabular}

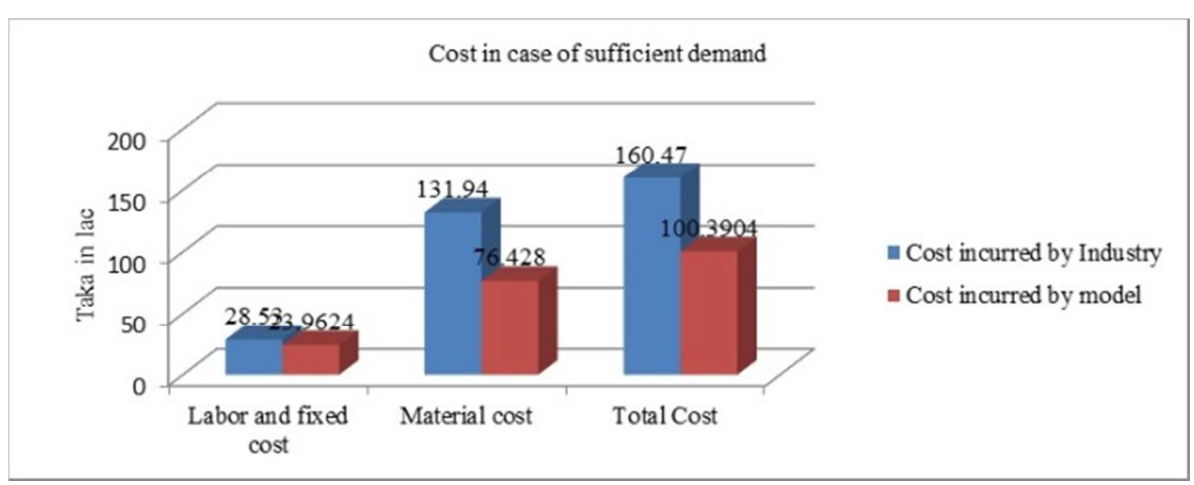

Figure 4. Cost minimization in case of sufficient demand (amount in lac Taka). 
Table 8. Cost minimization in case of request consideration.

\begin{tabular}{llll}
\hline Type of cost & Industry (Taka) & Model (Taka) & Percentage of decrease \\
\hline Fixed & $28,53,000$ & $26,19,100$ & 8 \\
Material & $1,31,94,000$ & $7,469,800$ & 43 \\
Total & $1,60,47,000$ & $1,00,88,900$ & 37.13 \\
\hline
\end{tabular}

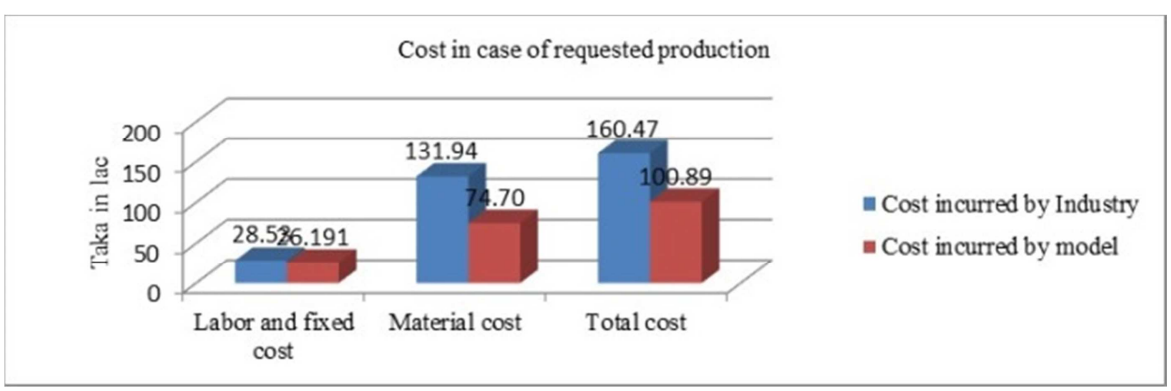

Figure 5. Cost minimization in case of requested production (amount in lac Taka).

Table 9, figure 6, table 10 and figure 7 show that using the model material consumption can be decreased so that cost is reduced significantly.

Table 9. Fabric use in both the situations.

\begin{tabular}{llll}
\hline Situations & Used by industry & Used by model & Decrease in use by model \\
\hline Sufficient demand & 12156 & 11582.12 & $4.72 \%$ \\
Requested production & 12156 & 11832.29 & $2.66 \%$ \\
\hline
\end{tabular}

Quantities in Thousand Kilogram

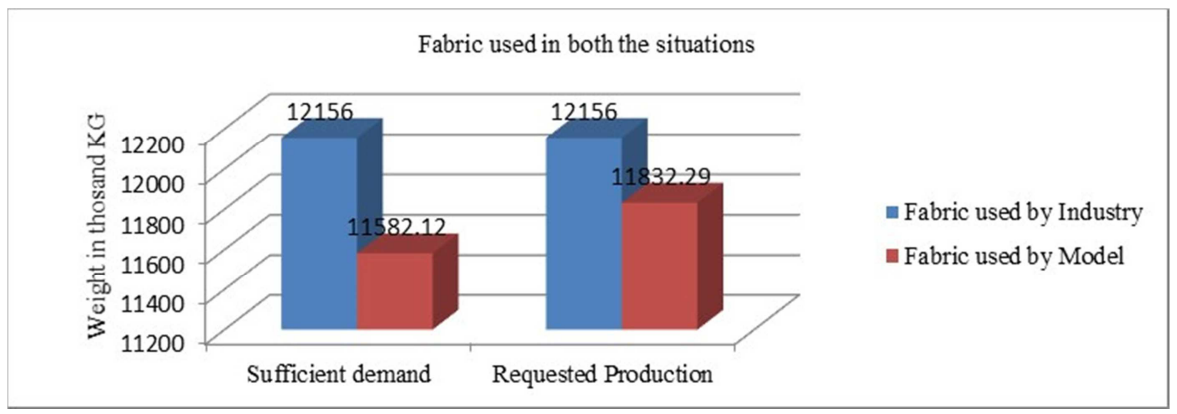

Figure 6. Fabric use in both the situations.

Table 10. Thread use in both the situations.

\begin{tabular}{llll}
\hline Situations & Used by industry & Used by model & Decrease in use by model \\
\hline Sufficient demand & 11295 & 10478.6 & $7.23 \%$ \\
Requested production & 11295 & 10701.8 & $5.25 \%$ \\
\hline
\end{tabular}

Quantities in Thousand Kilometer

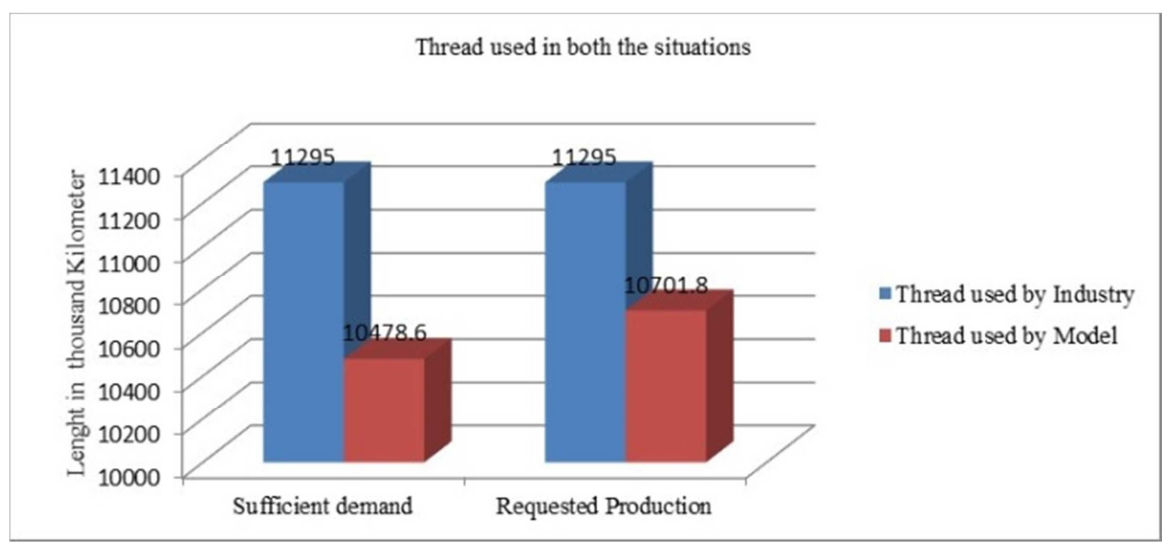

Figure 7. Thread use in both the situations. 


\section{Sensitivity Analysis}

Sensitivity analysis is the systematic change of the inputs to keep the optimal solution of a linear programming model unchanged. It helps an analyst to determine how the change of one variable can affect the outcome of the problem. This is also known as post optimality analysis. Some data coefficients or parameters of the linear programming model may be controllable. SA helps us to study the effect of changes in these parameters on the optimal solution. If the optimal value changes by a considerable amount for a small change in the given parameters, then it may be worthwhile to implement some of these changes.

In order to analyze sensitivity of profit we have considered $10 \%$ increase in consumption of fabric, thread, material cost and sewing time. Table 11 and figure 8 show that the profit decreases by $0.23 \%, 1.33 \%, 1.85 \%$ and $7.37 \%$ respectively with respect to the profit earned by the LPP model we formulated. On the other hand, if the consumptions are decreased then the profit increases accordingly. This is noted here that the consumption of sewing time affects the profit in a greater extent than that of other processes.

Table 11. Sensitivity of profits in cases of $10 \%$ increasing consumptions.

\begin{tabular}{lll}
\hline Parameters & Profit (Taka in lac) & Decreases in profit (\%) \\
\hline Fabric consumption & 34.13 & 0.23 \\
Thread consumption & 33.75 & 1.33 \\
Material cost & 33.57 & 1.85 \\
Sewing time & 31.69 & 7.37 \\
\hline
\end{tabular}

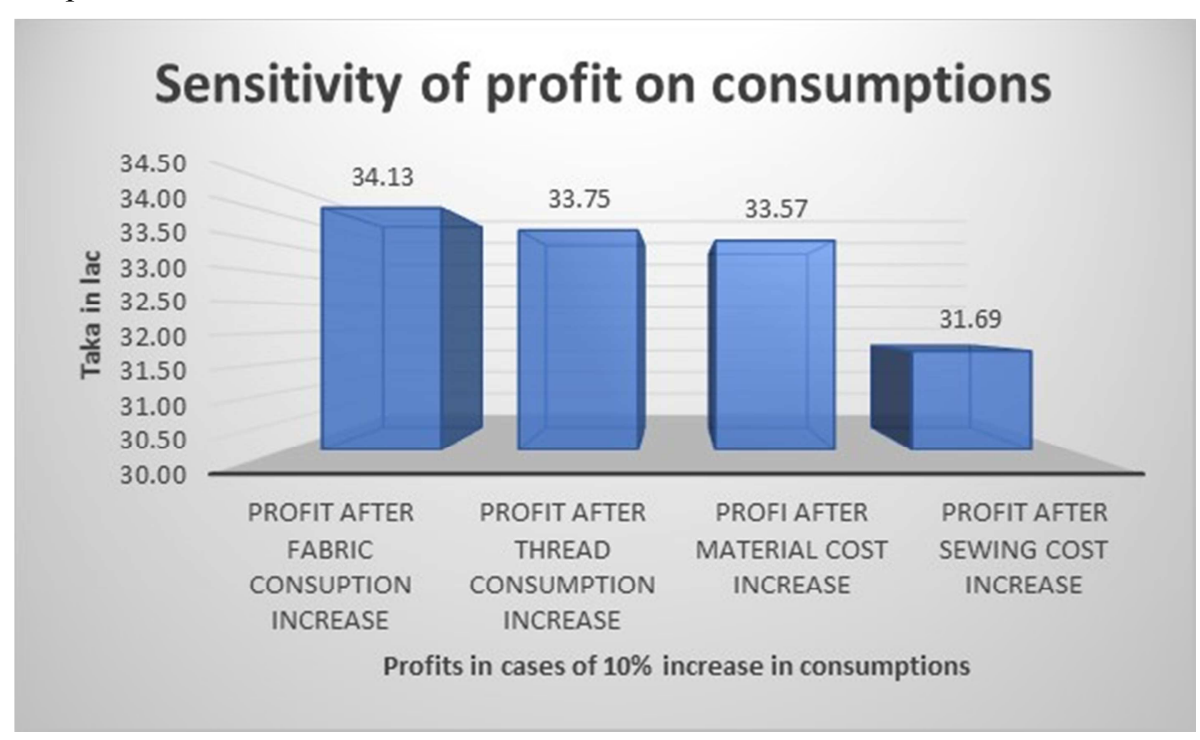

Figure 8. Profits earned in various cases with increasing consumptions.

\section{Conclusion}

Using proposed LPP model developed in this paper, the profit of the case company can be increased by $21.08 \%$ when there is sufficient demand and that can be $12.33 \%$ when clients' requests are to be met. The cost can be decreased by around $37 \%$ in both the situations. Using less quantities of fabric and thread remarkable profit can be increased. The model suggests that the industry can earn more profit by employing quick production strategy and method in their sewing sector for producing quality garment items in stipulated time which also reduces production lead time. The profit increment and improvement in resource utilization can enhance the global competitiveness of the company.

This research would create further pathways to accomplish substantial research on other manufacturing industries based on local and international perspectives.

\section{Acknowledgements}

We are grateful to the University Grant Commission of
Bangladesh (UGC) has given its full support and funding in favour of this research work. Dhaka University of Engineering and Technology, Gazipur (DUET) has shown its generous cooperation in this regard. Bangladesh University of Engineering and Technology (BUET) provided insight and expertise that greatly assisted the research work. Wega Knitex Limited, Gazipur in Bangladesh has given full cooperation providing us data along with information for this study. We are very much grateful to all of them although they may not agree with all of the interpretations of this paper.

\section{References}

[1] Uddin, M. F. and Sano, K. (2012). Coordination and Optimization: The Integrated Supply Chain Analysis with NonLinear Price-Sensitive Demand, An International Journal of Optimization and Control: Theories \& Applications, 2, 1, 83-94.

[2] Jokar, M. R. and Sajadieh, M. S. (2009). Optimization a Joint Economic Lot Sizing Problem with Price-sensitive Demand, Transaction E: Industrial Engineering, 16, 2, 159-164. 
[3] Qin, Y., Tang, H. and Guo, C. (2007). Channel Coordination and Volume Discounts with Price-sensitive Demand. Int. J. Production Economics, 105, 43-53.

[4] Uddin, M. F. and Sano, K. (2010). Mixed Integer Linear Fractional Programming for Integrated Supply Chain Network Design and Optimization, International Journal of Business and Economics, 2, 1, 57-70.

[5] Uddin, M. F. and Sano, K. (2011). Coordination, Supply Chain Optimization and Facility Location Selection Problem, Journal of Society for Transportation and Traffic Studies, 2, 3, 18-32.

[6] Islam, M. K., Uddin, M. F. and Alam, M. M. (2014). Supply Chain Optimization by Mixed Integer Program for Manufacturer and Retailer System of Poultry Firm in Bangladesh, Journal of Bangladesh Mathematical Society, 34, 75-87.

[7] Islam, M. K., Uddin, M. F. and Alam, M. M. (2015). Comparison and Supply Chain Optimization of Poultry Firm Using Mixed Integer and Linear Fractional Program. IOSR Journal of Mathematics, 11, 1, 40-54.

[8] Momaya, K. (2008). Evaluating Country Competitiveness in Emerging Industries: Learning from a Case of Nanotechnology, Journal of International Business and Economy, 9, 1, 37-58.

[9] Nandita, B. and Hasan, M. B. (2017). A Sophisticated Forecasting Method for a Garments Company in Bangladesh, International Journal of Pure and Applied Mathematics, 117, $14,145-156$.
[10] Kumar, V. (2010). JIT Based Quality Management: Concept and Implications in Indian Context. International Journal of Engineering Science and Technology, 2, 1, 40-50.

[11] Ezema, B. I. and Amakom, U. (2012). Optimizing Profit with the Linear Programming Model: A Focus on Golden Plastic Industry Limited, Enugu, Nigeria. Interdisciplinary Journal of Research in Busness, 2, 2, 37-49.

[12] Yalçinsoy, A., Zincirkiran, M. and Tiftik, H. (2014). Approach of Capacity Planning Through Linear Programming Technique: A Practice in Textile Enterprise. International Journal of Innovative Research in Management, 3, 3, 16-29.

[13] Campo, E. A., Cano, J. A., Andres, R. and Montoya, G (2018). Linear Programming for Aggregate Production Planning in a Textile Company. Fabric and Textiles in Eastern Europe, 26, 5 (131), 13-19.

[14] Woubante, G. W. (2017). The Optimization Problem of Product Mix and Linear Programming Application: Case Study in the Apparel Industry. Open Science Journal, 2, 2, 111 .

[15] Tesfaye, G., Berhane, T., Zenebe, B. and Asmelash, S. (2016). A Linear Programming Method to Enhance Resource Utilization Case of Ethiopian Apparel Sector. International Journal for Quality Research, 10, 2, 421-432. 